\title{
Study of vibration control using laboratory test rig of wind turbine tower-nacelle system with MR damper based tuned vibration absorber
}

\author{
P. MARTYNOWICZ* \\ AGH University of Science and Technology, Department of Process Control, 30 Mickiewicza Ave., 30-059 Krakow, Poland
}

\begin{abstract}
Wind turbine tower dynamic stress is related to the fatigue wear and reliability of the whole wind turbine structure. This paper deals with the problem of tower vibration control using a specially designed and built laboratory model. The considered wind turbine tower-nacelle model consists of a vertically arranged stiff rod (representing the tower), and a system of steel plates (representing nacelle and turbine assemblies) fixed at its top. The horizontally aligned tuned vibration absorber (TVA) with magnetorheological (MR) damper is located also at the top of the rod (in nacelle system). Force excitation sources applied horizontally to the tower itself and to the nacelle were both considered. The MR damper real-time control algorithms, including ground hook control and its modification, sliding mode control, linear and nonlinear (cubic and square root) damping, and adaptive solutions are compared to the open-loop case with various constant MR damper input current values and system without MR TVA (i.e., MR TVA in "locked" state). Comprehensive experimental analyses and their results are presented.
\end{abstract}

Key words: wind turbine vibration, tower-nacelle laboratory model, tuned vibration absorber, MR damper, tower vibration control.

\section{Introduction}

One of the emerging renewable energy sectors nowadays is wind turbines industry. Wind turbines are ecological solutions; however, their implementation cost is significant. Structural vibration and its consequences imply appropriately high investment into construction process and it is one of the greatest contributors to the total amount of wind farm implementation costs. The wind load (and also sea waves load for the offshore structures) which varies in time as well as rotation of turbine elements are the major contributors to the structural vibration of tower and blades. Cyclic stress that the tower is subjected to may lead to the decrease in reliable operation time due to structure fatigue wear [1] or even failure accident. Tower vibration arises due to various excitation sources as variable wind conditions, including wind shear, Karman vortices, blade passing effect, differences in inflow conditions for each of the blades, rotating elements unbalance, generator operation, sea waves, ice, etc [2]. This vibration is generally lightly damped, especially considering low aeroelastic damping for the first tower lateral mode [3-6]. The lateral modes are excited due to Karman vortices, generator operation, sea waves' variable load and rotating machinery unbalance, rather than due to direct wind load variation and blade passing effect, as for longitudinal modes. In the project presented, only the tower vibration is analyzed.

The solutions utilized to reduce wind turbines towers' vibration include collective blade pitch control, generator electromagnetic torque control [7-9], and passive, semi-active, or active tuned vibration absorbers (TVAs) [10-13]. TVAs are widely spread structural vibration reduction solutions for slender structures. In the standard (passive) approach, TVA consists of the

*e-mail: pmartyn@agh.edu.pl additional moving mass, spring and viscous damper, which parameters are tuned to the selected (most often first) mode of vibration $[10,14]$. Passive TVAs work well at the load conditions characterized with a single frequency to which they are tuned, but cannot adapt to wide excitation spectrum [15], thus more advanced TVAs are considered to change or tune TVA operating frequency. Among them, magnetorheological (MR) TVAs are placed [15], as using MR damper (instead of viscous damper) guarantees a wide range of resistance force, fast response times, low sensitivity to temperature change and fluid contamination, high operational robustness, and minor energy requirements as compared with active systems [16-18]. As simulations and experiments show, implementation of MR damper in TVA system may lead to further vibration reduction in relation with passive TVA (subject of author's separate publications).

Within the scope of current project, tower-nacelle simulation and laboratory models (Figs. 1 and 2) were specially developed and built, in which all turbine components (nacelle, blades, hub, shaft, generator and possibly gearbox) are represented by nacelle concentrated mass and mass moments of inertia. The laboratory test rig of wind turbine tower-nacelle system offers the possibility of modeling tower vibration under various aerodynamic, hydrodynamic, mechanical unbalance, changeable electromagnetic load, and other excitation sources (listed above), since horizontal concentrated force (designated by $F_{s}(t)$ ) generated by dedicated shaker may be applied to the nacelle, or to the tower itself at different heights if necessary. Several initial modes of vibration may be analyzed. The rig may also be laid down on the horizontally excited platform to model vibration of buoy-floating wind turbine structures, or vibration due to seismic excitation.

Various approaches to the problem of wind turbine tower vibration control with MR TVA are presented. With the use of MR damper, standard TVA linear (viscous) damping algorithm may 
be realized as well as more advanced controllers. Throughout them, ground hook control and its modification, sliding mode control, linear and nonlinear damping, and adaptive control algorithms are implemented, in comparison to open-loop solutions with several MR damper input current values and system without TVA (i.e. TVA in "locked" state). Only the first bending mode of vibration is analyzed here. Two independent, horizontal, concentrated force excitation sources are considered: the first one applied to the nacelle, the second one, to the tower midpoint.

The paper is organized as follows. In the forthcoming section, wind turbine tower-nacelle model is introduced. Then, laboratory test rig with measurement and control system is presented. Vibration control algorithms are followed by the experimental results. The paper ends with several conclusions.

\section{Wind turbine tower-nacelle model}

The model to be analyzed (Fig. 1) consists of stiff rod (Tower) arranged vertically, representing wind-turbine tower, and a stiff body connected rigidly to the top of the rod, representing both nacelle and turbine assemblies (Nacelle). The bottom end of the rod is fixed to the ground via additional foundation. As the first tower bending mode has dominant modal mass participation (ca. fivefold greater than the next mode), vibration reduction system that comprises spring and MR damper (built in parallel) with an additional stiff body (Absorber), operating all together as TVA, is located at the top of the tower (at Nacelle). The horizontal disturbance load, provided in the laboratory conditions by the dedicated modal shaker, may either be concentrated at the nacelle, or applied to the arbitrary tower section; both locations enable forcing tower bending modes of vibration. The MR TVA direction of operation is the same as the direction of applied excitation (assuming small bending angles).

Based on all the assumptions, constraints and thorough analyses results that are covered in [19-21], Ti Gr. 5 rod was selected to model wind turbine tower, while Lord Co. RD 1097-1 [17] was utilized as TVA MR damper. The parameters of TVA were tuned for the first bending mode of vibration $[10,14]$. The absorber mass $m_{2}$ after several system reconfigurations was selected to be ca. $15 \%$ of the modal mass of the first bending mode of tower-nacelle model $m_{1}$ (i.e. mass ratio was $\mu=m_{2} / m_{1}=0.152$ ).

\section{Laboratory test rig}

A laboratory test rig of wind turbine tower-nacelle system (Fig. 2) was built according to the details specified above. It consists of a vertically oriented titanium (Ti Gr.5) rod 1 (representing wind-turbine tower), and a system of steel plates 2 (representing nacelle and turbine assemblies) fixed to the top of the $\operatorname{rod} 1$, with MR TVA embedded. The titanium rod is rigidly mounted to adequately large and stiff steel foundation frame 3. MR TVA 4 is an additional mass moving horizontally along linear bearing guides, connected with the system representing nacelle via spring and Lord RD 1097-1 MR damper [17] in parallel. RD 1097-1 damper (whose force depends on the current fed to its coil) is an actuator of such a vibration reduction system. MR TVA operates along the same direction as vibration excitation applied to the system. Force generated by vibration excitation system, i.e., the Modal Shop lightweight electrodynamic force exciter 5 of 2060E series (TMS 2060E) [22] with drive train assembly 6 of changeable leverage (enabling changeable force, displacement and velocity ranges) may be applied either to the rod 1 (modelling the tower, as in the picture) or to the set of steel plates 2 modelling nacelle/turbine. Excitation signal is generated by LDS Dactron 7 and amplified by the Modal Shop 2100E21-400 unit 8 . Such a laboratory test rig gives the possibility to model wind turbine tower vibration under several excitation sources [19-21].

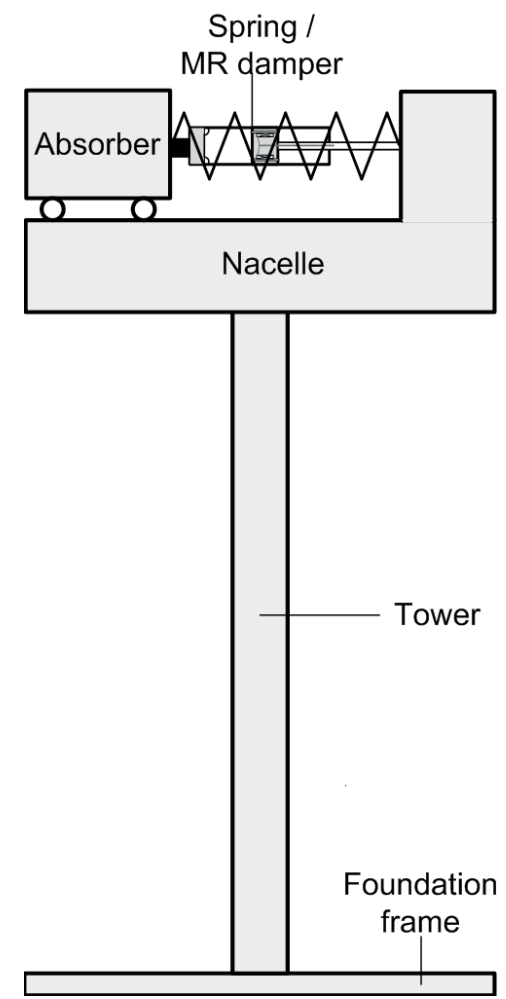

Fig. 1. Sketch of the tower-nacelle model with MR TVA

Measurement and control system (Fig. 3) consists of laser displacement transducer / laser vibrometer with its controller 9 for rod 1 tip (and system 2) horizontal displacement $\left(x_{1}\right)$ / velocity $\left(\dot{x}_{1}\right)$ measurement, laser displacement transducer 10 for rod 1 midpoint horizontal displacement measurement $\left(x_{0}\right)$ (at half of rod length), LVDT transducer 11 for system $2-$ TVA 4 relative displacement $\left(x_{1}-x_{2}\right)$ measurement, tensometric stress transducers $12, \mathrm{MR}$ damper force $\left(P_{M R}\right)$, shaker force, and acceleration transducers (not apparent in Fig. 2), as well as transducers supply/amplifying/conditioning system including MR damper current controller 13, and measuring-control PC 14 with MATLAB/Simulink/RT-CON applications (signals designations listed in brackets). The operation of MR damper current controller is apparent in Fig. 7 - see time pattern of measured control voltage $u_{M R}\left(v s\right.$. measured current $i_{M R}$ ) as an 

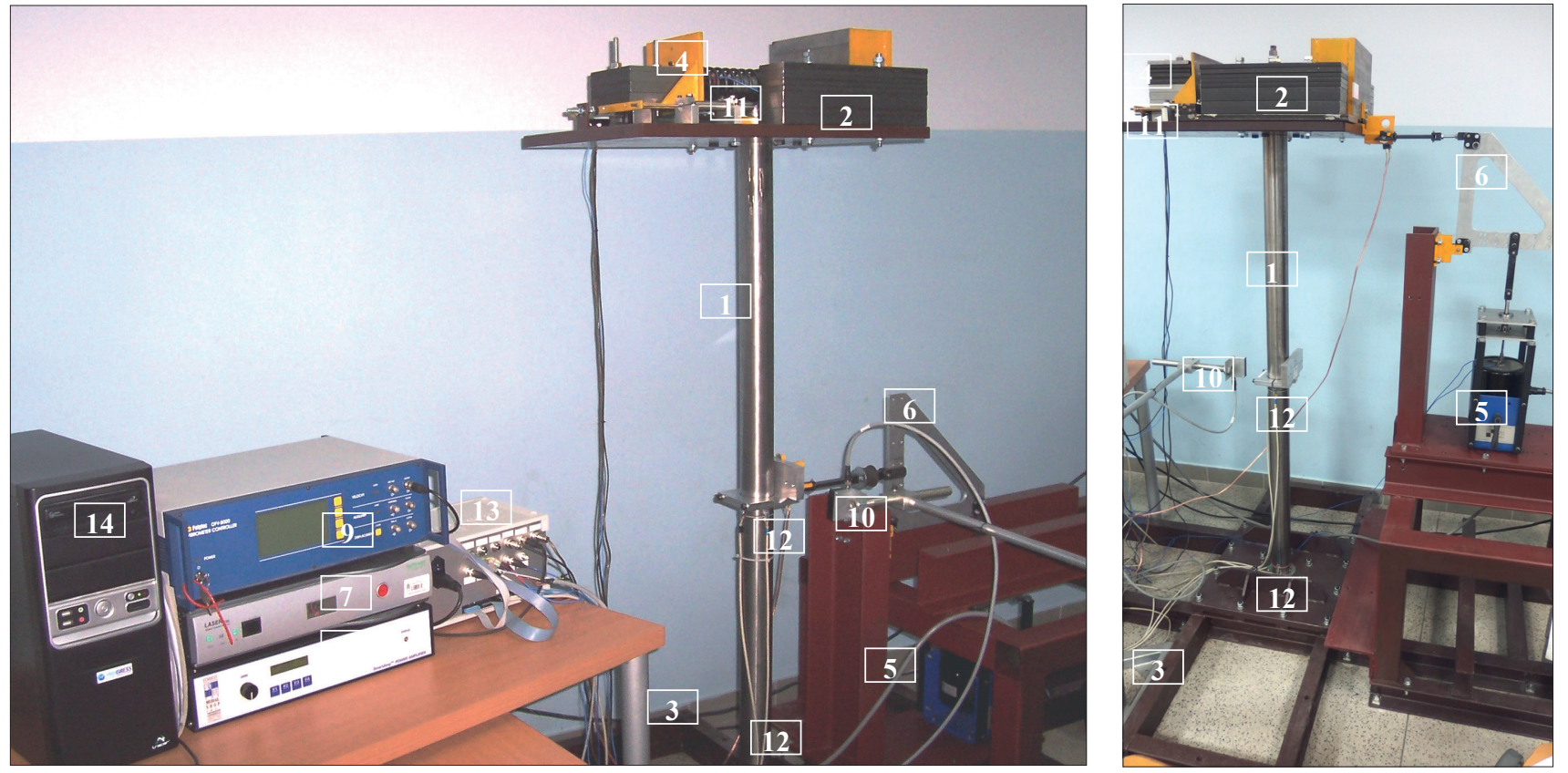

Fig. 2. Laboratory test rig: excitation applied to the tower midpoint (left) or to the nacelle (right)

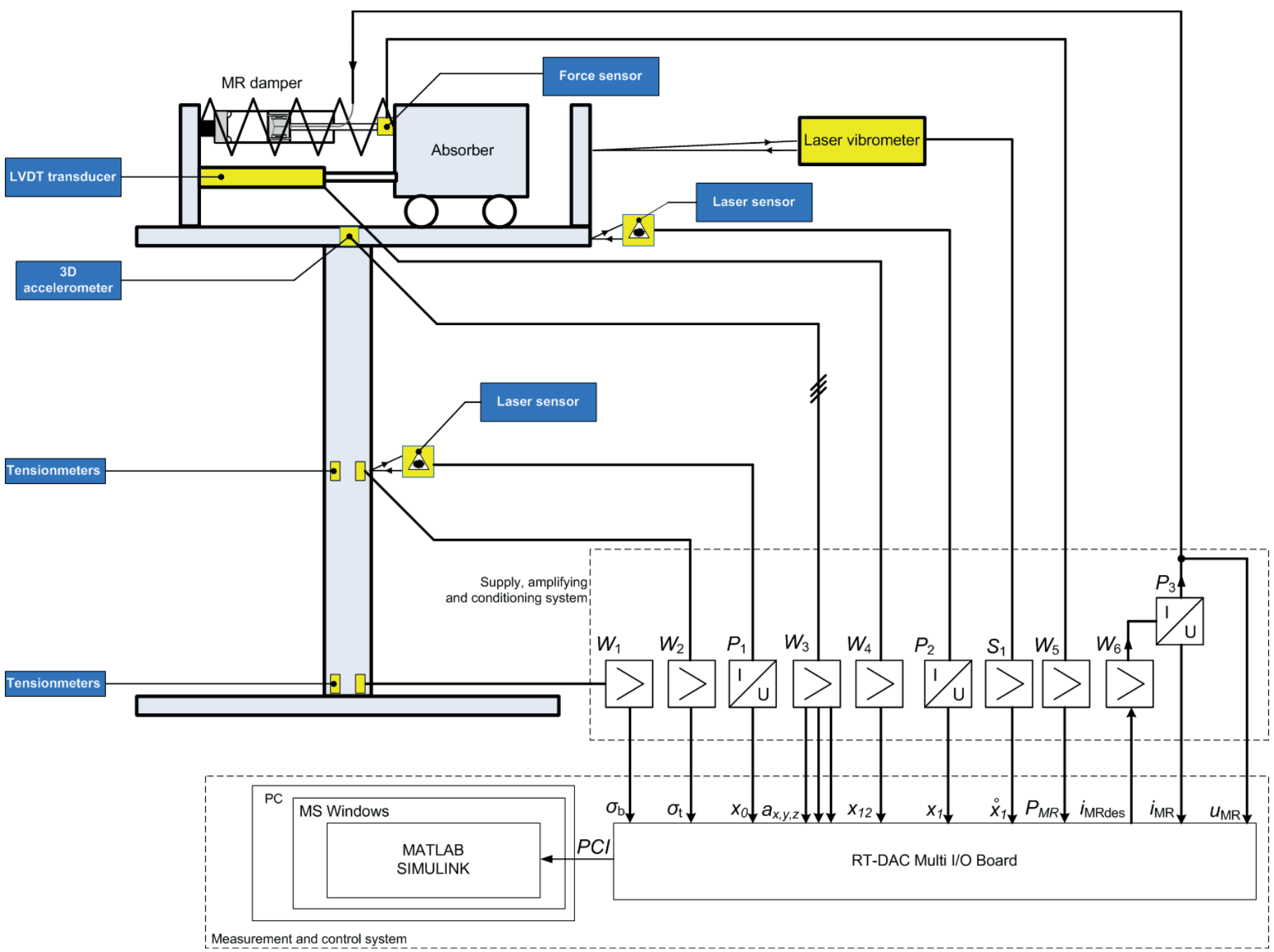

Fig. 3. Measurement and control system diagram 
output of analogue PID controller embedded in 13 to force required current pattern. Data acquisition and control system diagram is presented in Fig. 3.

Selected test rig parameters are presented in Table 1, while the entire identification problem is covered in [23]. FFTs exhibiting averaged $1^{\text {st }}\left(f_{1}=3.45 \mathrm{~Hz}\right)$ and $2^{\text {nd }}\left(f_{2}=30.52 \mathrm{~Hz}\right)$ bending frequencies of the laboratory and simulation models [23-26], obtained from the experimental $\left|x_{0}(f)\right|$ and simulation $\left|x_{0 M}(f)\right|$ rod midpoint horizontal displacement series, are presented in the Fig. 4.

Table 1

Parameters of tower-nacelle laboratory test rig.

\begin{tabular}{|l|c|}
\hline Parameter & Value \\
\hline Length of the rod (tower) $\left[10^{-3} \mathrm{~m}\right]$ & 1507 \\
\hline Diameter of the rod $\left[10^{-3} \mathrm{~m}\right]$ & 70.50 \\
\hline Mass of the rod $[\mathrm{kg}]$ & 26.06 \\
\hline $\begin{array}{l}\text { Mass of the system located at the top of the rod (nacelle) } \\
\text { W/o TVA }[\mathrm{kg}]\end{array}$ & 163.40 \\
\hline TVA absorber mass $[\mathrm{kg}]$ & 25.78 \\
\hline TVA optimal stiffness coefficient $\left[10^{3} \mathrm{~N} / \mathrm{m}\right]$ & 13.41 \\
\hline TVA optimal damping coefficient $[\mathrm{Ns} / \mathrm{m}]$ & 227.2 \\
\hline
\end{tabular}

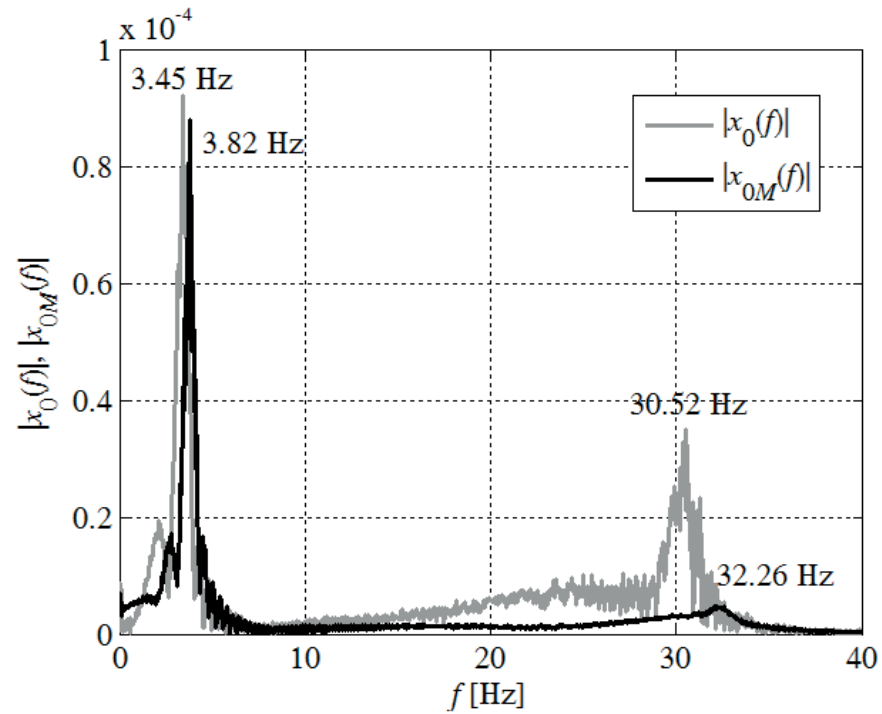

Fig. 4. FFTs calculated from experimental $\left(\left|x_{0}(f)\right|\right)$ and simulation $\left(\left|x_{0 M}(f)\right|\right)$ rod midpoint displacement patterns (presented in a separate publication on test rig identification [23])

\section{Vibration control}

Considering nonzero MR damper response time and value of the $2^{\text {nd }}$ bending mode frequency (separate publication on test rig identification), the main purpose of vibration reduction system and TVA implementation was to reduce amplitudes of $x_{0}$ (rod midpoint) and $x_{1}$ (rod tip or nacelle) horizontal displacements corresponding to $1^{\text {st }}$ tower-nacelle bending mode, thus TVA location was selected to be at the nacelle [19, 21, 24, 26]. In this paper, selected approaches to the problem of wind turbine tower-nacelle system vibration control with MR TVA are pre- sented using specially developed and built laboratory test rig, on the basis of previous thorough simulations and preliminary experiments including $1^{\text {st }}$ and $2^{\text {nd }}$ bending mode of vibration analyses that are presented in $[24,26]$. Since it was observed that $2^{\text {nd }}$ bending mode of vibration reduction possibilities for the system with MR TVA are negligible, only the $1^{\text {st }}$ mode of vibration is analyzed here. Using MR damper, standard TVA linear damping algorithm [10] implementation results (designated by $C$ ) are compared with results of ground hook (GND) and modified ground hook (Mod.GND), sliding mode (SMC), nonlinear damping including cubic $(C 3)$ and square root damping $(S Q R T)$, adaptive $(A D P T)$ and open-loop solutions with constant MR damper input current of $0.0 \mathrm{~A}, 0.1 \mathrm{~A}$, and $0.2 \mathrm{~A}$, and system with TVA "locked" by one-sided bolt and MR damper input current of $1.0 \mathrm{~A}$.

Two independent force excitation sources are considered. The force (designated by $F_{s}$ ) applied to the rod 1 itself at half of its height through the drive train assembly 6 (see Fig. 2) represents direct or indirect external (aerodynamic, sea waves, ice, etc.) tower loads that may be reduced to the resultant concentrated force applied at half of tower height. The load applied horizontally to the system 2 modelling the nacelle $\left(P_{s}\right)$ represents mainly wind thrust on the tower top / nacelle through the rotor.

The aim of MR damper implementation was to improve TVA vibration reduction capabilities in relation with standard (passive) solution with linear damper of constant damping coefficient, especially to decrease displacement amplitudes corresponding to the two local maxima apparent in the frequency response of typical structure with TVA. Real-time control strategies implemented to determine MR damper input current are listed below. The author's idea of ground-hook algorithm modification is discussed elaborately at the end of the section, as other control strategies are only mentioned here following their introduction in [26] and partially in [24].

4.1. Linear damping (C). In this approach, MR damper is used to emulate linear (viscous) damper of optimally tuned TVA damping coefficient $c_{2}$ with $k_{2}$ being optimally tuned stiffness coefficient $[10,14,24,26]$. As previous results proved, the laboratory model is more damped than simulation one (and that compromised MR damper control possibilities) due to e.g. MR damper pre-yield component that is most significant at low velocities, absorber linear bearing guides friction, interfacial slip in joints, linear damping with reduced $c_{2}$ value $\left(0.6 c_{2}\right)$ was also tested (designations $1 C$ or $0.6 C$ ).

Internal feedback P-controller loop (alternatively to PI-controller [27] with settings as in [24, 26]) with MR damper real-time force measurement is implemented in such a force follow-up algorithm [24, 26, 27]. P-controller proportional gain is 0.04 , saturation limits are $(0,1) \mathrm{A}$, and a measurement signal scaling factor (alpha) is equal to 0.75 .

Apart from P (PI) loop with MR damper force measurement (Fig. 3) operating as MR damper force follow-up algorithm, for selected (most adequate) algorithm versions control current may also be determined with the use of MR damper hyperbolic tangent inverse model Simulink implementation, which inputs are desired force, relative displacement and velocity, and output is 
control current for the damper [26]. Analysis concerning the use of inverse model with hysteresis or without was conducted, as hysteresis introduced ambiguity. If MR damper inverse model was used instead of P (PI) control loop, designation in graphs/ table $I N V$ is present, while for $\mathrm{P}(\mathrm{PI})$ follow-up algorithm designation $P(P I 1)$ is apparent.

4.2. Nonlinear damping (C3 and SQRT). This solution is MR damper based implementation of nonlinear damping [26-28] in (MR) TVA system. Two approaches considered here are:

- cubic damping with MR damper desired force calculated as: $P^{\text {desired }}=K_{3} c_{2}\left(\dot{x}_{1}-\dot{x}_{2}\right)^{3}$, with several $K_{3}$ values: $K_{3}=50$, $K_{3}=150, K_{3}=250$, and $K_{3}=500$ selected on the basis of simulation and experimental analyses (designations: C3 50, C3 150, C3 250, and C3 500, respectively),

- square-root damping with MR damper desired force calculated as: $P_{M R}^{\text {desired }}=K_{1 / 2} c_{2} \operatorname{sgn}\left(\dot{x}_{1}-\dot{x}_{2}\right) \sqrt{\left|\dot{x}_{1}-\dot{x}_{2}\right|}$, with $K_{1 / 2}=0.05, K_{1 / 2}=0.15, K_{1 / 2}=0.25$, and $K_{1 / 2}=0.45$ selected on the basis of previous analyses (designations in graphs: $S Q R T$ 0.05, SQRT 0.15, SQRT 0.25 and SQRT 0.45, respectively). Both nonlinear damping approaches comprise force follow-up control algorithms mentioned in Linear damping $(C)$ section, and selected versions use MR damper inverse model.

4.3. Adaptive control (ADAPT). An adaptive control implemented here is based on utilizing MR damper to emulate controllable stiffness and controllable viscous damping in such a way that TVA stiffness $k^{\text {adapt }}=k^{\text {desired }}$ and damping $c_{2}^{\text {adapt }}=c_{2}^{\text {desired }}$ coefficients are tuned to the excitation frequency rather than to tower-nacelle system $1^{\text {st }}$ bending frequency (as $k_{2}$ and $c_{2}$ in Linear damping (C) section), using dependencies $[10,14,26]$. Additionally, solutions with reduced damping coefficient, i.e. $c^{\text {adapt }}=0.6 c_{2}^{\text {desired }}$, and $c_{2}^{\text {adapt }}=0$ were analyzed (designation: $A D A P T$ 1C, ADAPT 0.6C or ADAPT OC) - damping reduction at the frequency to which TVA is tuned should lead to vibration mitigation at this frequency (equal to excitation frequency; applicable for single-frequency excitation spectrum). Thus, real-time determination of excitation frequency is followed by real-time calculation of TVA required stiffness: $P_{\text {stiff }}=k_{2}^{\text {adapt }}\left(x_{1}-x_{2}\right)$, and damping: $P_{\text {damp }}=c_{2}^{\text {adapt }}\left(\dot{x}_{1}-\dot{x}_{2}\right)$ forces, leading to MR damper desired force formula:

$$
P_{M R}^{\text {desired }}=\left(k_{2}^{\text {adapt }}-k_{2}\right)\left(x_{1}-x_{2}\right)+c_{2}^{\text {adapt }}\left(\dot{x}_{1}-\dot{x}_{2}\right) \text {, }
$$

where $k_{2}$ is spring stiffness determined on the basis of standard TVA tuning to tower-nacelle system $1^{\text {st }}$ bending frequency. As MR damper cannot deliver energy to the system, force (8) cannot be exactly mapped either. Thus, a dedicated force follow-up PI-based control algorithm was specially developed [26] with $(0,1)$ A saturation range (designation in graphs: PI2). PI controller settings were as in [26]. Alternatively inverse model was used (INV).

4.4. Sliding mode control (SMC). Sliding mode (nonlinear control strategy) is widely used due to its robustness and ability to decouple high-dimension systems into a set of independent lower-dimension subsystems [29, 30]. Only the dynamics of the $1^{\text {st }}$ bending mode modal mass with TVA was considered, with sliding surface: $s=x_{1}+\dot{x}_{1}$. MR damper input current $i_{M R}$ control law may be expressed by [29]:

$$
i_{M R}=\left\{\begin{array}{cc}
i_{M R}^{\max }, & \operatorname{sign}\left[s\left(\dot{x}_{1}-\dot{x}_{2}\right)\right]=1 \\
0, & \operatorname{sign}\left[s\left(\dot{x}_{1}-\dot{x}_{2}\right)\right] \neq 1
\end{array},\right.
$$

where $i_{M R}^{\max }=0.25, i_{M R}^{\max }=0.5$, or $i_{M R}^{\max }=1.0$ A values were selected (designations: SMC 0.25, SMC 0.5, SMC 1.0) [26].

4.5. Ground-Hook control (GND). The implementation of this simple strategy for slender structures provides vibration reduction (with relation to the ground) that is most efficient at the point of (MR) TVA / GND application. The MR damper input current $i_{M R}$ control algorithm (displacement ground-hook version) is represented by the formula:

$$
i_{M R}=\left\{\begin{array}{cc}
i_{M R}^{\max }, & x_{1}\left(\dot{x}_{1}-\dot{x}_{2}\right) \geq 0 \\
0, & x_{1}\left(\dot{x}_{1}-\dot{x}_{2}\right)<0
\end{array} .\right.
$$

On the basis of previous analyses $i_{M R}^{\max }=0.25$, or $i_{M R}^{\max }=0.5$ were selected (designations: GND 0.25, GND 0.5) [26].

4.6. Modified Ground-Hook control (Mod.GND). The ground-hook modification idea presented here is based on standard displacement version of ground hook algorithm as mentioned above. In formula (3), MR damper input current is intended to be maximal when signs of structure absolute displacement $x_{1}$ and structure-TVA relative velocity $\dot{x}_{1}-\dot{x}_{2}$ are the same. It was observed, however, that MR damper force should be maximal when signs of structure absolute displacement $x_{1}$ and MR damper force $P_{M R}$ are the same (rather than signs of $x_{1}$ and $\dot{x}_{1}-\dot{x}_{2}$ ). During sine excitation test, for some part of the period MR damper behaves as an "active" device (observing force-velocity plot in Fig. 5). Although velocity $\dot{x}_{1}-\dot{x}_{2}$ sign is opposite to displacement $x_{1}$ sign, MR damper force sign $P_{M R}$ is the same as $x_{1}$ sign, thus it may be used for vibration mitigation by maximizing MR damper force in that time (Figs. 6 and 7). As can be seen in Figs. 7 and 8, Mod.GND control is much more precise as it concerns time instants at which damper force should be increased (resulting in $A\left(x_{1}\right)$ reduction), as compared to GND control. This situation appears for a short part of sine period and results from MR damper hysteresis phenomenon. This is not the case in TVA system with viscous damper.

The idea underlying the modified ground-hook algorithm implemented on MR damper takes a simple form:

$$
i_{M R}=\left\{\begin{array}{c}
i_{M R}^{\max }, \quad x_{1} P_{M R} \geq 0 \\
0, \quad x_{1} P_{M R}<0
\end{array}\right.
$$

with emphasis put on bias cancellation algorithm for both $x_{1}$ and $P_{M R}$ signals; $i_{M R}^{\max }=0.25$, or $i_{M R}^{\max }=0.5$ (designations: Mod. GND 0.25, Mod.GND 0.5) were selected on the basis of previous simulation and experimental analyses [26]. 


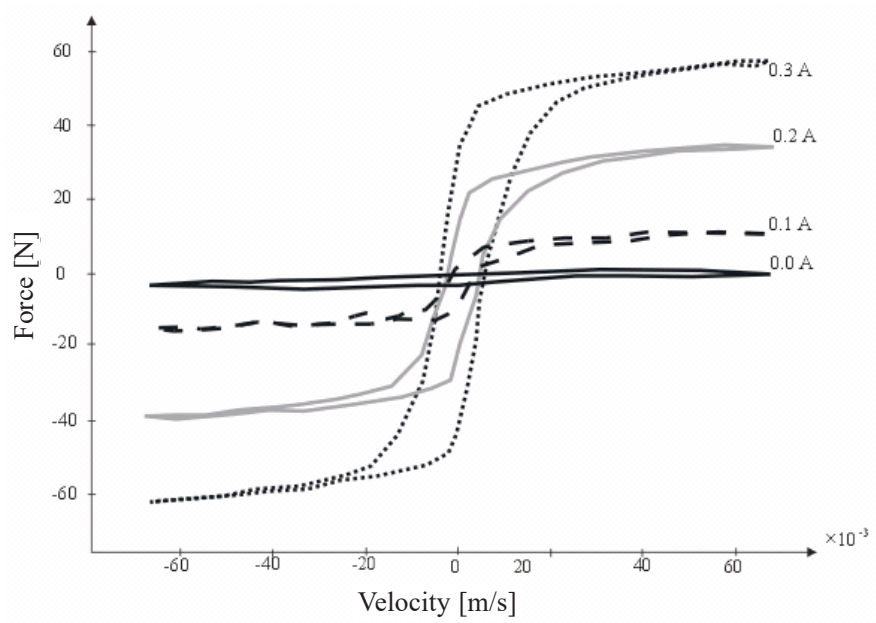

Fig. 5. RD 1097-1 exemplary force-velocity plots, sine excitation

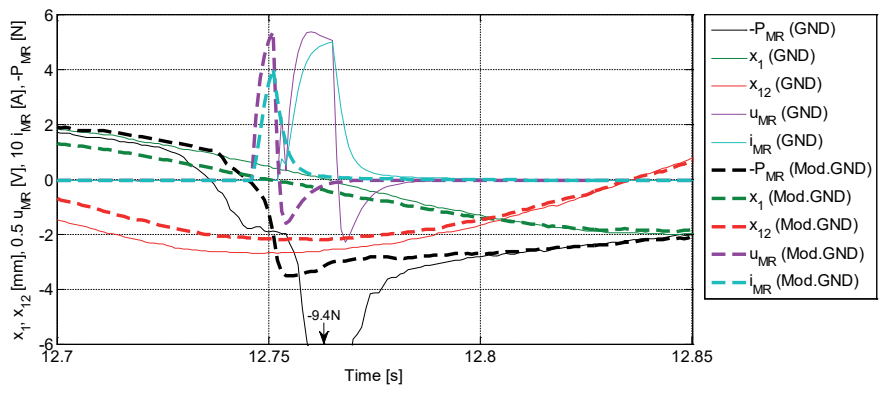

Fig. 6. Modified ground hook underlying idea, $f=2.95 \mathrm{~Hz}$, GND0.5 vs. Mod.GND0.5 (see Fig. 15)

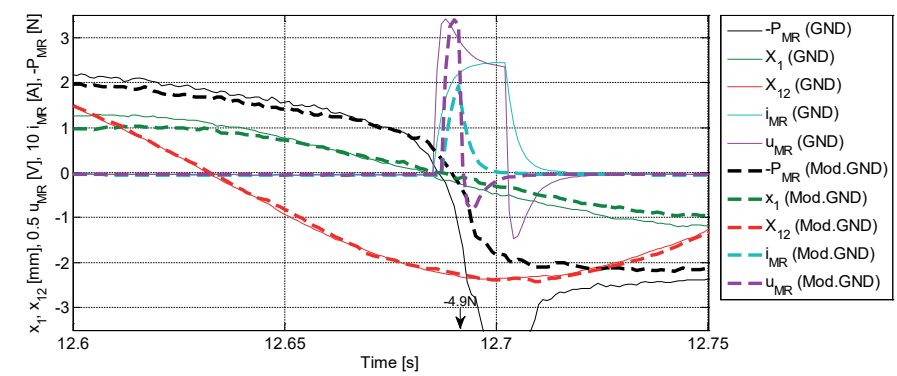

Fig. 7. Modified ground hook underlying idea, $f=3.45 \mathrm{~Hz}$, GND0 .25 vs. Mod.GND0.25 (see Fig. 15)

\section{Laboratory tests}

Initial laboratory tests as well as system identification and dynamic similarity analysis procedures and results are presented as separate publications [23-26].

The control algorithms presented in previous section were implemented and tested on the laboratory test rig in comparison with open-loop (passive) system with constant MR damper input currents: $0.0 \mathrm{~A}, 0.1 \mathrm{~A}$, and $0.2 \mathrm{~A}$, standard $L Q G$ approach [31] and a system without TVA in operation (TVA "locked"). Whether linear or nonlinear damping, or adaptive solution was used (demanding determination of control current on the basis of calculated desired force), desired force was augmented by minus kinetic friction force produced, during operation of absorber linear bearing guides, that was estimated to be of the order of $1 \mathrm{~N}$ using MR damper force sensor (Fig. 3 ) with the damper "locked" by $1.0 \mathrm{~A}$ input current for constant velocity draw/pull test. Compensation of friction force was indicated in frequency characteristics by designation $F r$. Two excitation configurations were investigated during the tests, as in Fig. 2.

The first test aimed to determine amplitude of $x_{0}$ and $x_{1}$ output frequency response functions ( $\mathrm{A}\left(x_{0}\right), \mathrm{A}\left(x_{1}\right)$ respectively), so series of experiments were conducted at selected discrete sine excitation frequency points within the range of $(2.55,5.05) \mathrm{Hz}$ with a step of $0.1 \mathrm{~Hz}$, comprising $1^{\text {st }}$ bending frequency region of the system without TVA. The system was excited by a force of amplitude $A\left(F_{s}(\mathrm{t})\right)=150 \mathrm{~N}$ applied to the rod (tower) midpoint.

Figs. 8-13 present $\mathrm{A}\left(x_{0}\right)$ displacement amplitude output frequency response functions for open-loop and feedback systems with control current and control algorithms details included in figures' legends. Analogously, Figs. 14-19 present A $\left(x_{1}\right)$ output frequency response functions. Fig. 20 presents $A\left(x_{0}\right)$ and $A\left(x_{1}\right)$ output frequency response functions for the system without MR TVA (TVA "locked"). All of these characteristics are presented in combination with output frequency response functions of control system that was recognized as a best MR TVA option (concerning vibration frequency responses) on the experimental laboratory ground, i.e. Mod. GND algorithm with maximum control current of $0.5 \mathrm{~A}$. The maximum amplitudes obtained for Mod.GND are ca. 10 times smaller than for the system without TVA regarding the whole frequency range.

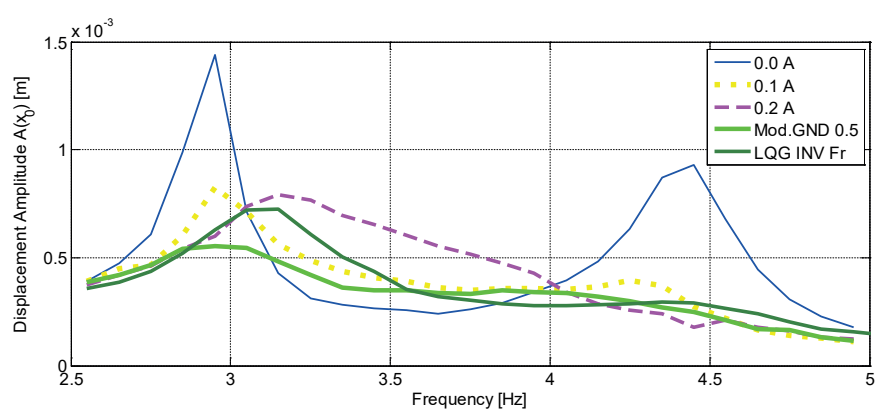

Fig. 8. Tower midpoint displacement amplitude $A\left(x_{0}\right)$ output frequency response functions for the system with MR TVA, $A\left(F_{s}(\mathrm{t})\right)=150 \mathrm{~N}$ (details in the text and in the legend)

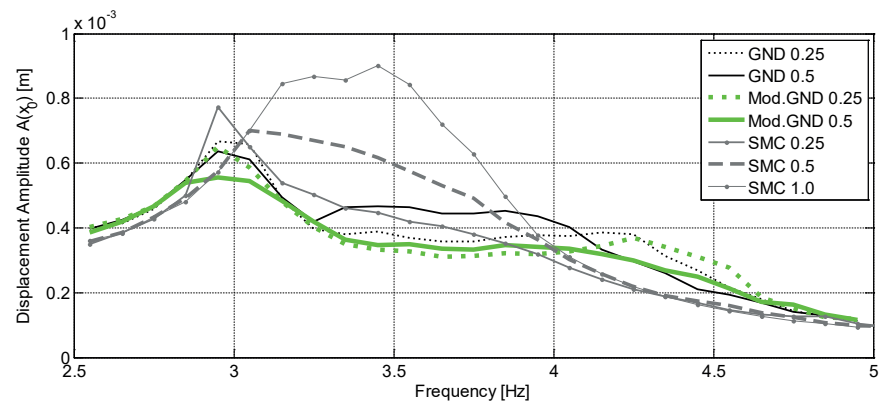

Fig. 9. Tower midpoint displacement amplitude $A\left(x_{0}\right)$ output frequency response functions for the system with MR TVA, $A\left(F_{s}(\mathrm{t})\right)=150 \mathrm{~N}$ 


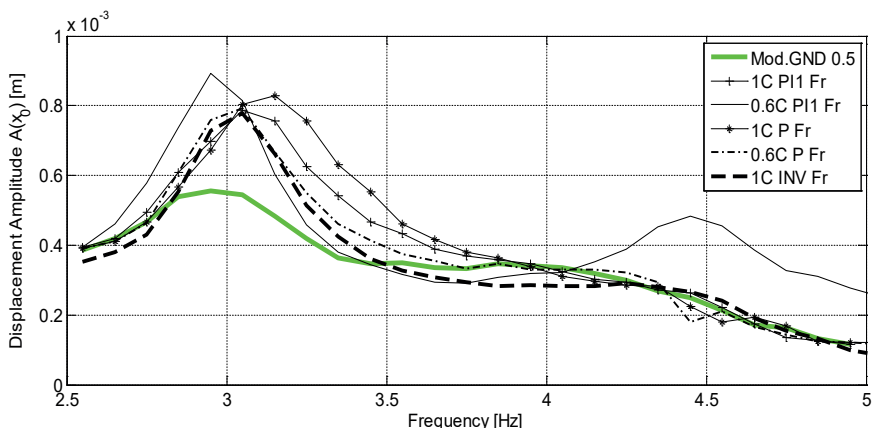

Fig. 10. Tower midpoint displacement amplitude $A\left(x_{0}\right)$ output frequency response functions for the system with MR TVA, $A\left(F_{s}(\mathrm{t})\right)=150 \mathrm{~N}$

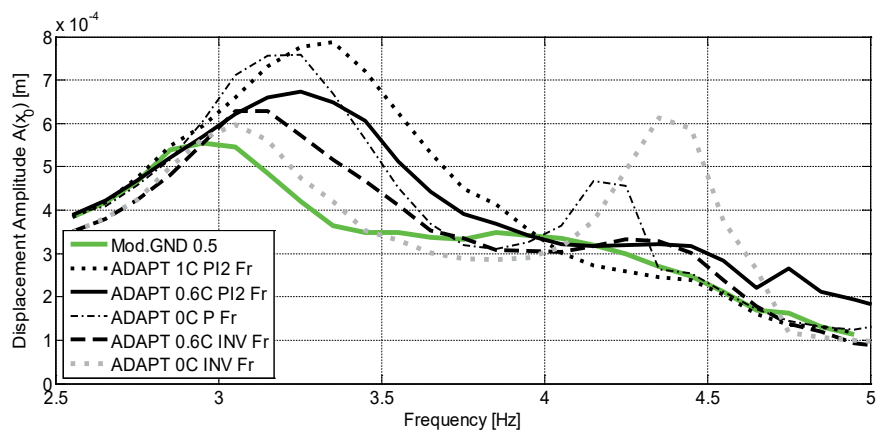

Fig. 11. Tower midpoint displacement amplitude $A\left(x_{0}\right)$ output frequency response functions for the system with MR TVA, $A\left(F_{s}(\mathrm{t})\right)=150 \mathrm{~N}$

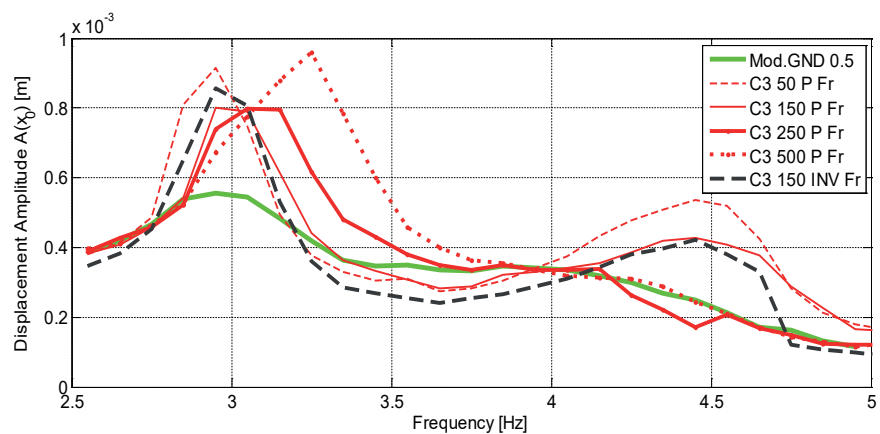

Fig. 12. Tower midpoint displacement amplitude $A\left(x_{0}\right)$ output frequency response functions for the system with MR TVA, $A\left(F_{s}(\mathrm{t})\right)=150 \mathrm{~N}$

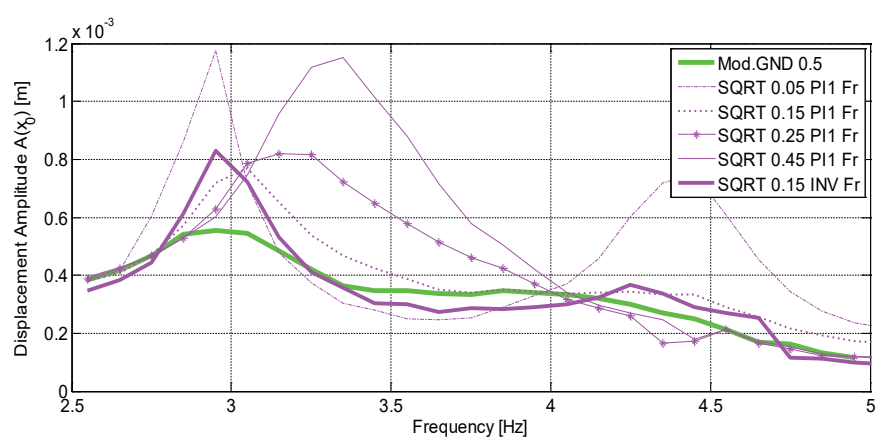

Fig. 13. Tower midpoint displacement amplitude $A\left(x_{0}\right)$ output frequency response functions for the system with MR TVA, $A\left(F_{s}(\mathrm{t})\right)=150 \mathrm{~N}$

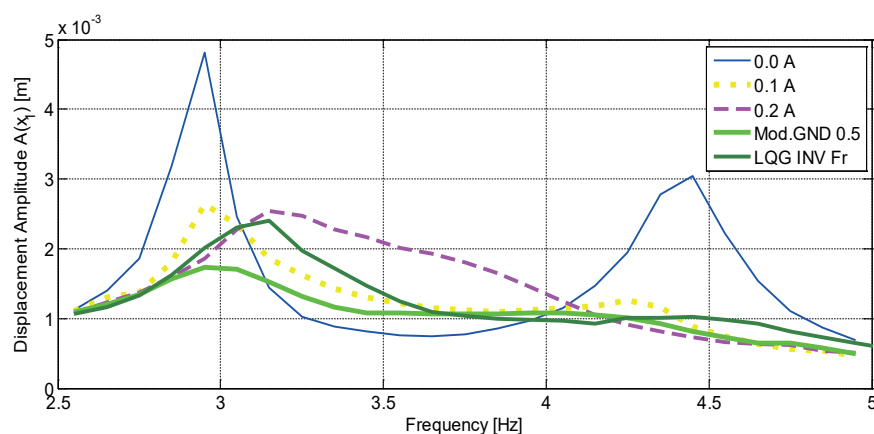

Fig. 14. Tower tip displacement amplitude $A\left(x_{1}\right)$ output frequency response functions for the system with MR TVA, $A\left(F_{s}(\mathrm{t})\right)=150 \mathrm{~N}$

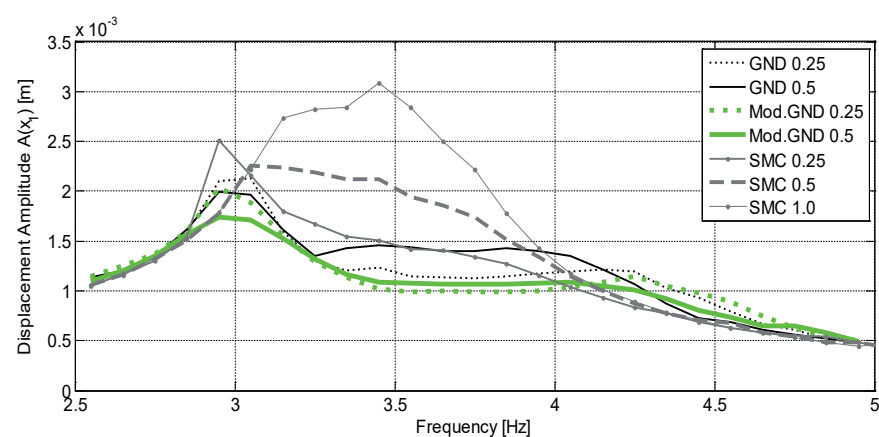

Fig. 15. Tower tip displacement amplitude $A\left(x_{1}\right)$ output frequency response functions for the system with MR TVA, $A\left(F_{s}(\mathrm{t})\right)=150 \mathrm{~N}$

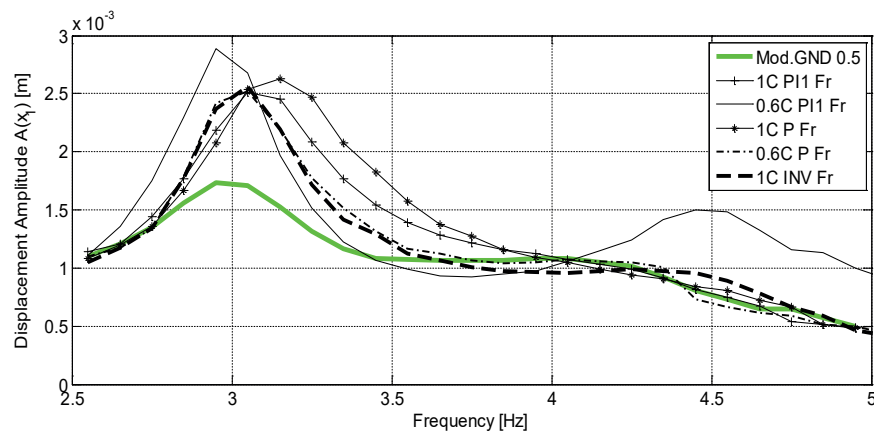

Fig. 16. Tower tip displacement amplitude $A\left(x_{1}\right)$ output frequency response functions for the system with MR TVA, $A\left(F_{s}(\mathrm{t})\right)=150$

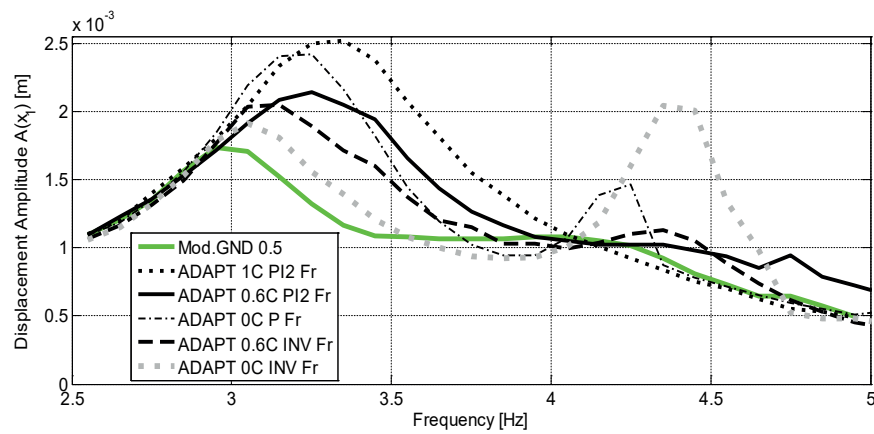

Fig. 17. Tower tip displacement amplitude $A\left(x_{1}\right)$ output frequency response functions for the system with MR TVA, $A\left(F_{s}(\mathrm{t})\right)=150 \mathrm{~N}$ 


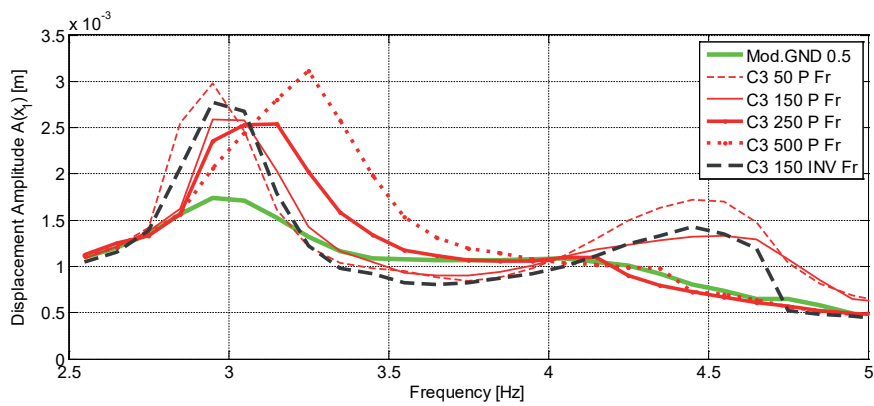

Fig. 18. Tower tip displacement amplitude $A\left(x_{1}\right)$ output frequency response functions for the system with MR TVA, $A\left(F_{s}(\mathrm{t})\right)=150 \mathrm{~N}$

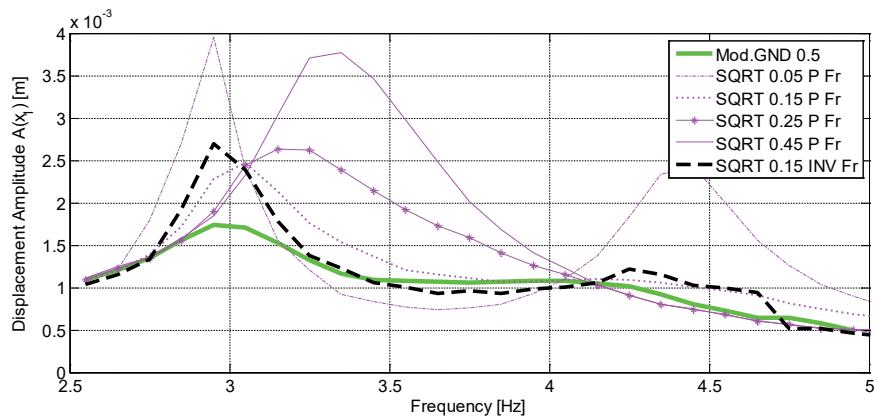

Fig. 19. Tower tip displacement amplitude $A\left(x_{1}\right)$ output frequency response functions for the system with MR TVA, $A\left(F_{s}(\mathrm{t})\right)=150 \mathrm{~N}$

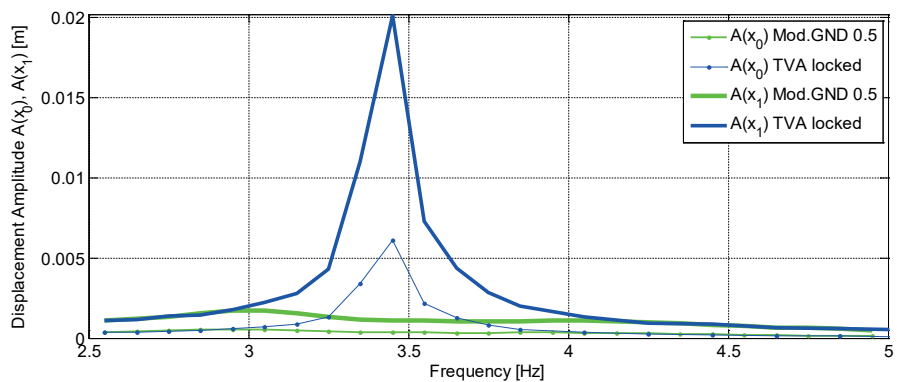

Fig. 20. Tower midpoint displacement amplitude $A\left(x_{0}\right)$ and tower tip displacement amplitude $A\left(x_{1}\right)$ output frequency response functions for the system with and without MR TVA, $A\left(F_{s}(\mathrm{t})\right)=150 \mathrm{~N}$

The next test was polyperiodic excitation applied both to the rod midpoint and to the system modelling the nacelle. The polyperiodic signal was a sum of the $1^{\text {st }}$ bending frequency $f_{1}=3.45 \mathrm{~Hz}$ and its second and third harmonics, and the $2^{\text {nd }}$ bending frequency of $f_{2}=30.52 \mathrm{~Hz}$. Amplitude of each of the monoperiodic wave was $150 \mathrm{~N}$ (regarding excitation at the rod/ tower midpoint $\mathrm{F}_{\mathrm{s}}$ ) or $48.75 \mathrm{~N}$ (regarding excitation at the nacelle $\mathrm{P}_{\mathrm{s}}$ ). As rod stiffness is inversely proportional to the length to the power of three, excitation applied to the system modelling the nacelle (although ca. three times smaller in amplitude) was more efficient in exciting the structure. Thus, it was selected for quantitative analysis (Table 2), while time responses obtained for rod midpoint excitation were used for graphical illustration (Fig. 21 ) only. The greater displacement amplitudes, the influence of friction forces of absorber linear bearing guides, MR damper sealing, MR damper pre-yield friction component etc. is less meaningful and so the inherent damping is smaller, i.e. more similar to the real-world case; thus, greater structure deflections were preferred. However, it was observed that for polyperiodic excitation test that does incorporate high frequency content, the shaker and drive train system's ability to generate and transfer adequately high forces was slightly limited, which was not the case for the single frequency excitation test (presented above).

Quality indexes obtained for the selected systems and excitation $\mathrm{P}_{\mathrm{s}}$ are gathered in Table 2 as amplitudes $(A(\bullet))$ of the steady state polyperiodic response. In each column of Table 2 , index for the system with zero control current and for best (considering that index) of the remaining systems are all distinguished in bold. Fig. 21 presents time sections of polyperiodic responses for the system with MR

TVA at $0.0 \mathrm{~A}$ and $0.1 \mathrm{~A}$ control current (the latter recognized as the most favourable passive system, according to the frequency domain analysis), response for the system with TVA "locked", and the system with Mod.GND algorithm as well as excitation force $F_{s}$ pattern. As can be observed, displacement $x_{0}$ exhibits both $1^{\text {st }}$ and $2^{\text {nd }}$ bending frequency for system with TVA, however for TVA "locked" $1^{\text {st }}$ mode of vibration is dominant ( $2^{\text {nd }}$ not visible) as its amplitudes are ca. 10 times greater than for the system with TVA in operation (TVA deals with $1^{\text {st }}$ mode reduction only while $2^{\text {nd }}$ mode is unaffected).

The system was then subjected to impulse excitation. The same selection of open-loop and feedback systems was made as for polyperiodic test. Considering the previously stated remark, response to the excitation applied to the system modelling the nacelle was used for quantitative analysis (Table 2), while excitation applied to the rod midpoint was used for graphical representation only. Results gathered in Table 2 are peak-peak displacements divided by two $((\max (\bullet)-\min (\bullet)) / 2)$ and root-meansquare displacements $(R M S(\bullet))$. Fig. 22 presents time plots of

(a)

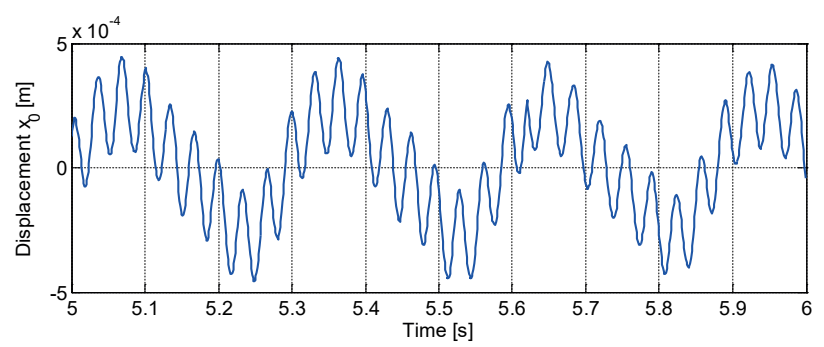

(b)

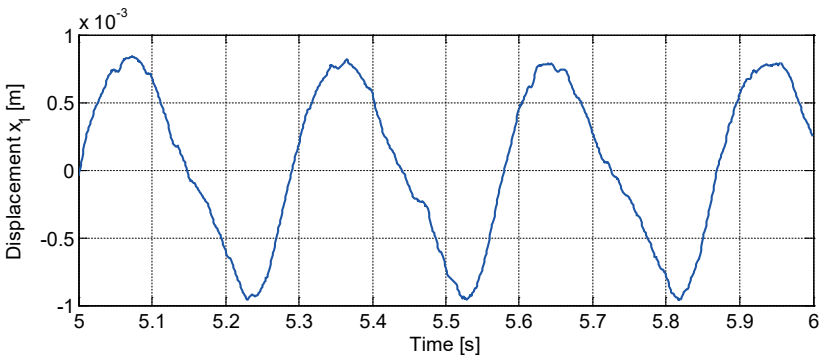

(c)

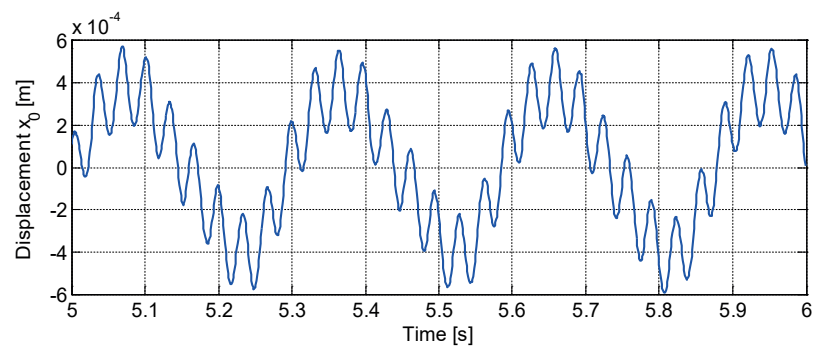


(d)

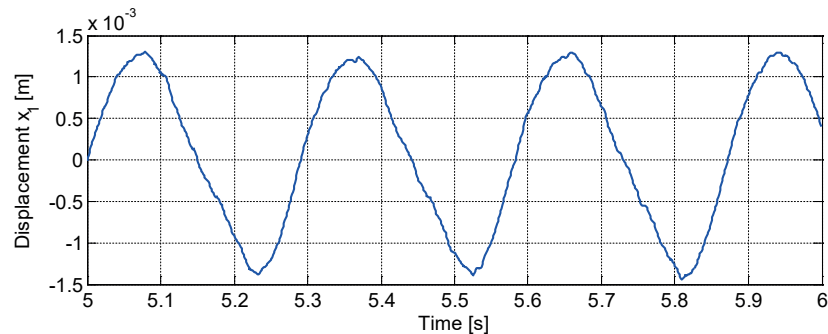

(e)

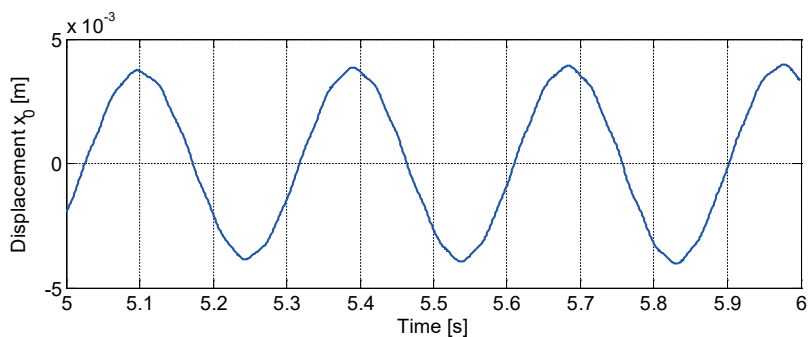

(f)

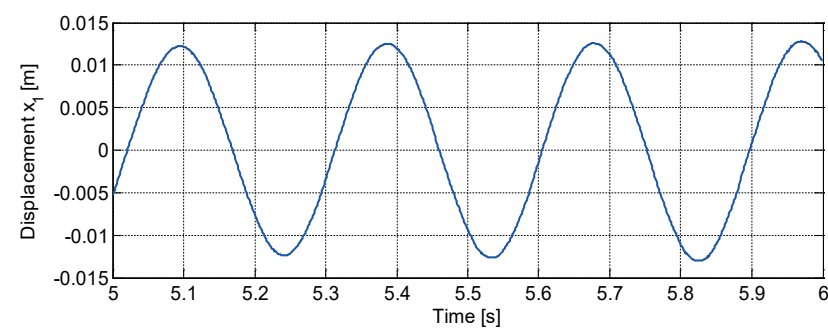

(g)

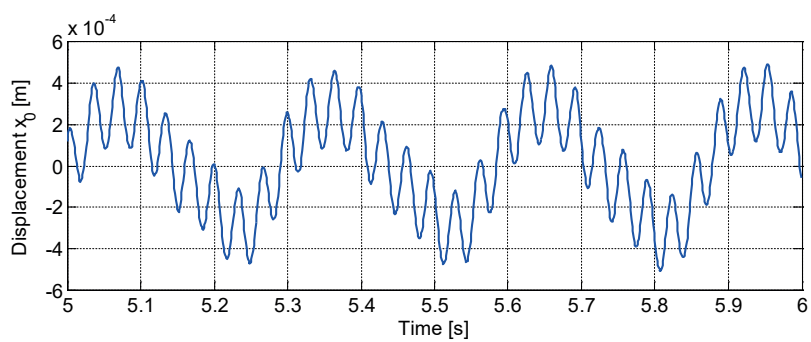

(h)

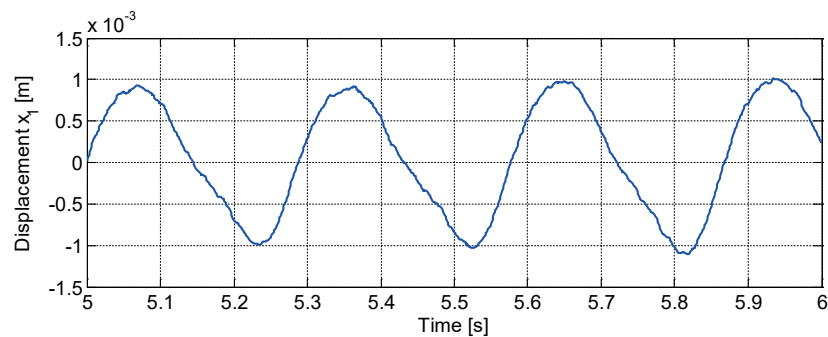

(i)

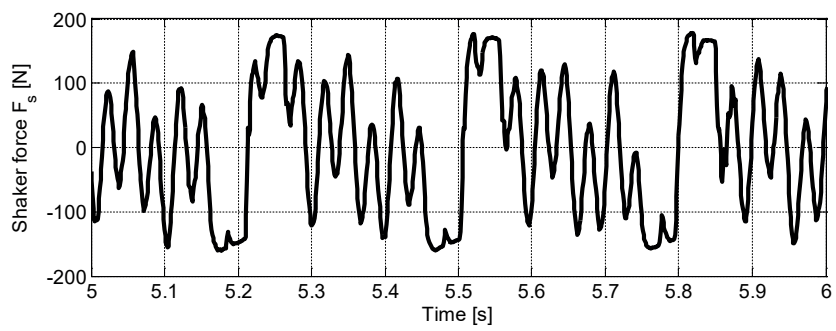

Fig. 21. Tower midpoint $x_{0}$, and tower tip $x_{1}$ displacement responses to polyperiodic excitation for the system: (a)(b) $0.0 \mathrm{~A}$, (c)(d) $0.1 \mathrm{~A}$, (e)(f) TVA locked, (g)(h) Mod.GND 0.5, and (i) excitation signal (a)

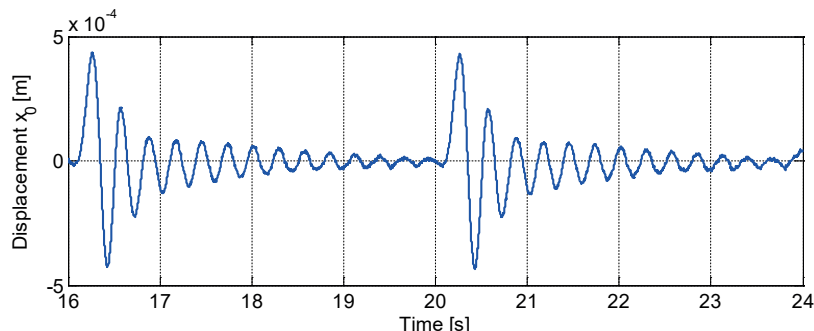

(b)

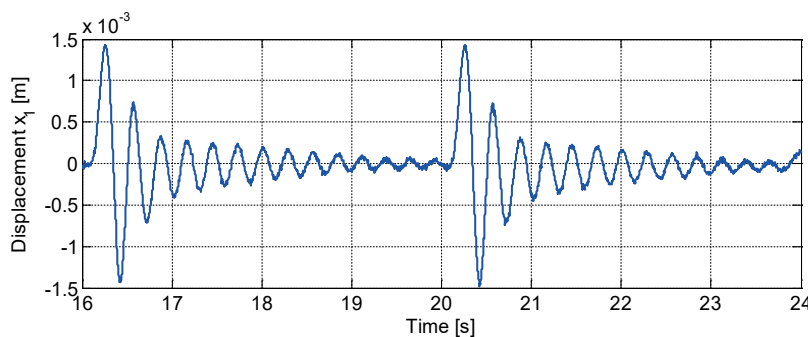

(c)

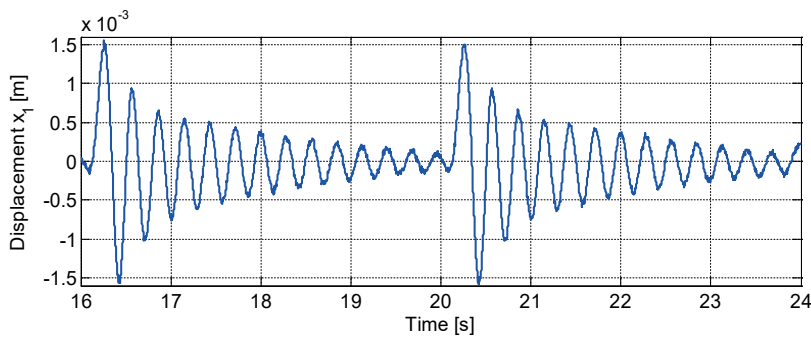

(d)

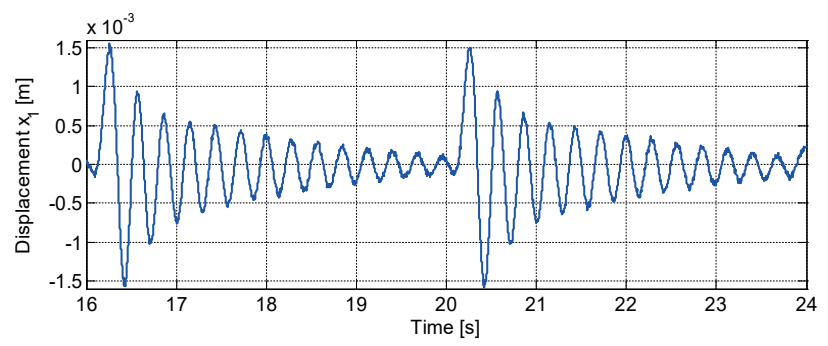

(e)

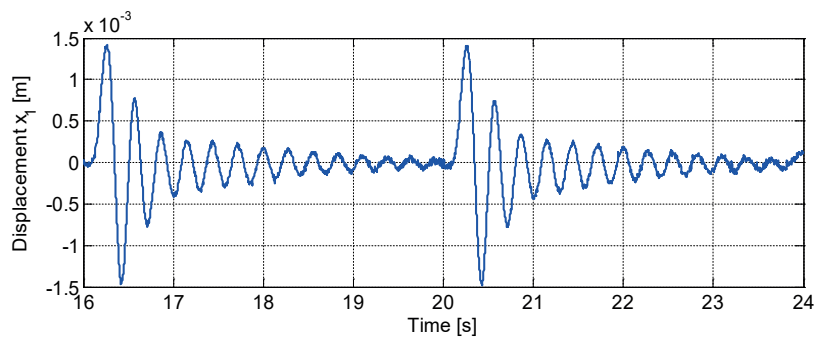

(f)

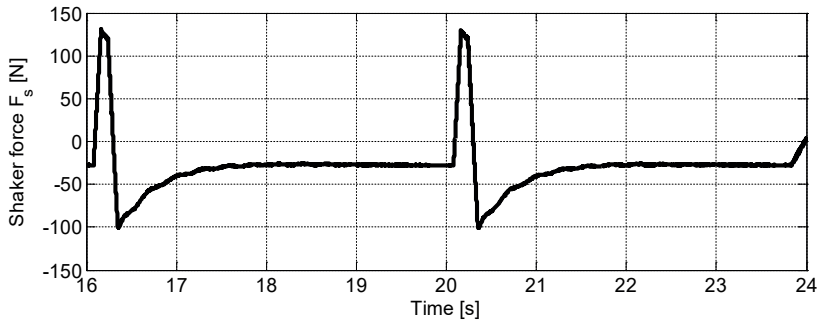

Fig. 22. Tower midpoint $x_{0}$, and tower tip $x_{1}$ displacement responses to impulse excitation for the system: (a)(b) $0.0 \mathrm{~A}$, (c) $0.1 \mathrm{~A}$, (d) TVA locked, (e) Mod.GND 0.5, and (f) excitation signal 
PAN www.journals.pan.pl

P. Martynowicz

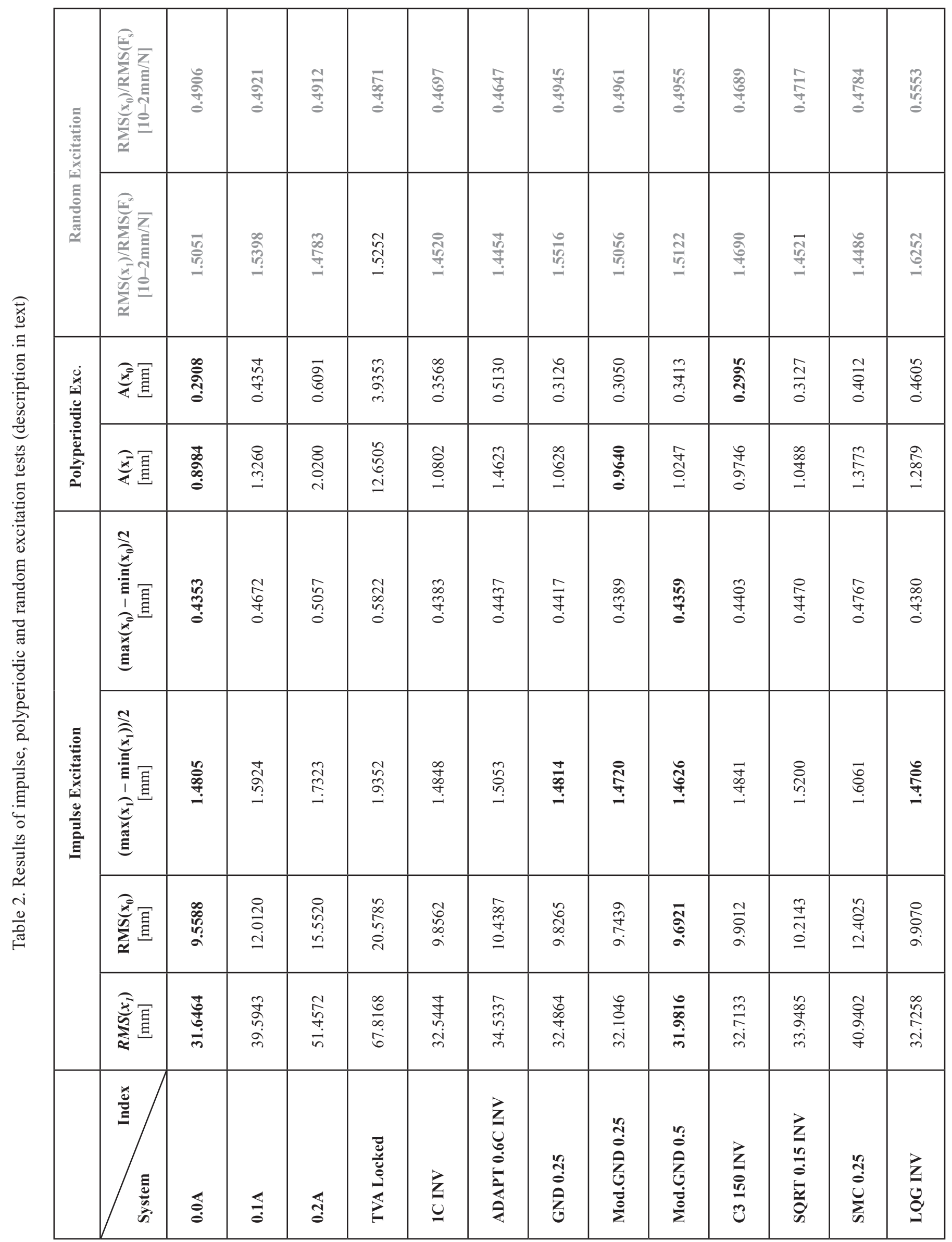


$x_{0}$ and $x_{1}$ impulse responses for the passive system with 0.0 A control current, and $x_{1}$ impulse responses for the system with 0.1 A, system with "locked" TVA, and for the system with Mod. GND algorithm (time patterns of $x_{0}$ are similar to the respective patterns of $x_{1}$ ), as well as the excitation force $\mathrm{F}_{\mathrm{s}}$ pattern.

The above results are slightly compromised as shaker was connected to the analyzed tower-nacelle model with the help of drive train system during the entire test. After impulse excitation, shaker armature damping influenced the response profile. To cope with that problem, free vibration reduction was considered as a following test with drive train system disconnected from the vibrating structure. Figs. 23-26 present results of such an analysis for selected open loop and feedback systems.

The problem of producing adequately large force excitation signals with high frequency content along with shaker armature damping also concerned semi-random excitation tests, including Davenport or Kaimal spectrum [32, 33], which were considered to model wind speed and aerodynamic forces acting on the wind turbine. Using power spectrum estimates [33], sever-

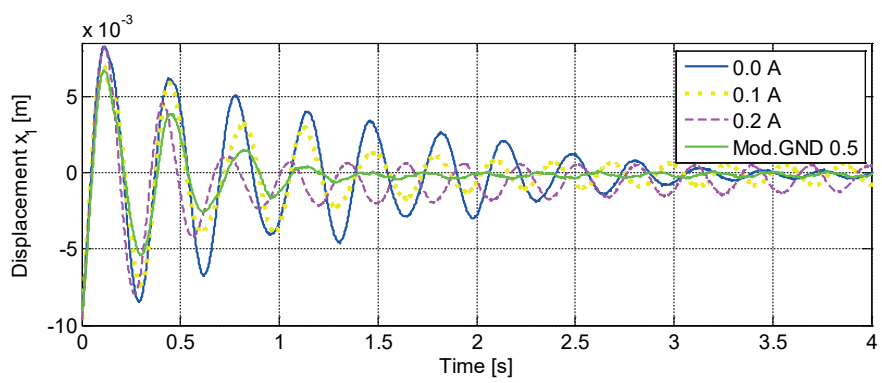

Fig. 23. Tower tip $x_{1}$ displacements time patterns - free vibration response (details in the text and in the legend)

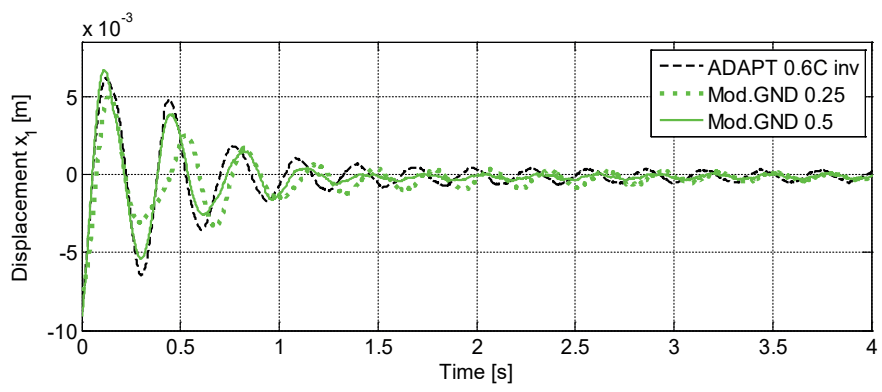

Fig. 24. Tower tip $x_{1}$ displacements time patterns - free vibration response

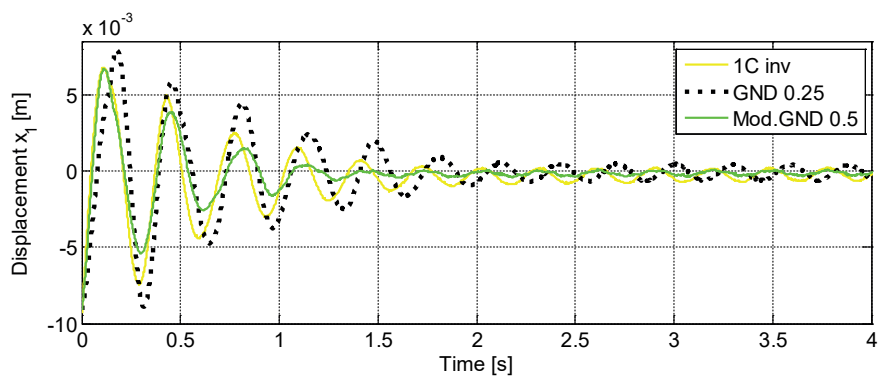

Fig. 25. Tower tip $x_{1}$ displacements time patterns - free vibration response

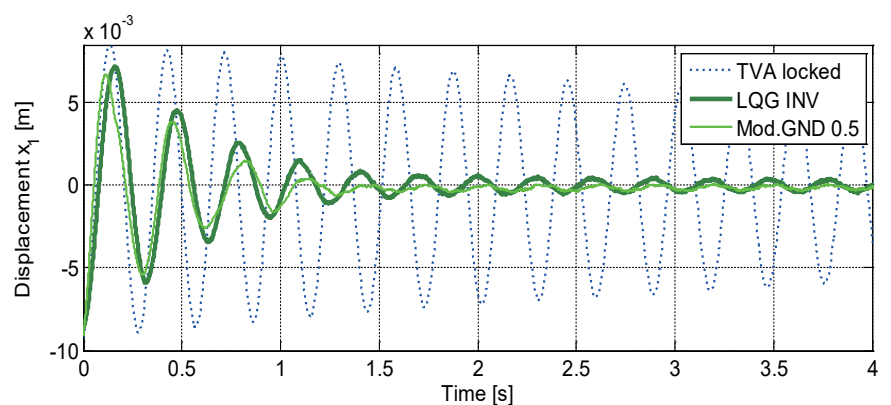

Fig. 26. Tower tip $x_{1}$ displacements time patterns - free vibration response

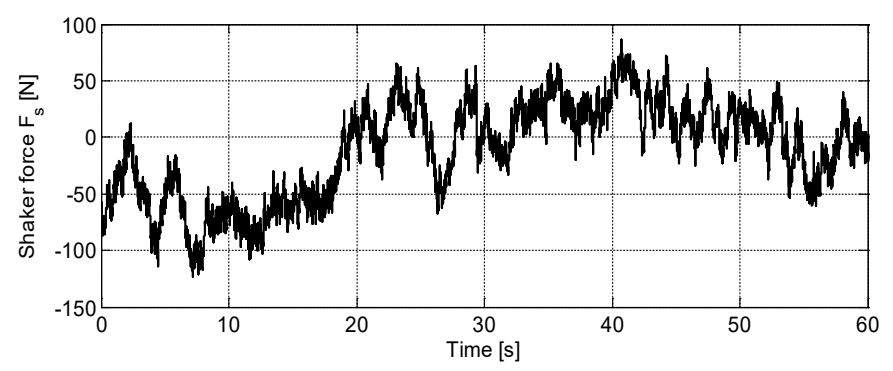

Fig. 27. Excitation realization profile generated using Davenport spectrum

al semi-random realizations were generated as a superposition of thousands of sine waves of different frequencies, random phases and amplitudes corresponding to the power of the particular frequency in the spectrum. The exemplary excitation realization profile generated using Davenport spectrum [33] is presented in Fig. 27 (patterns containing higher force content failed to be reproduced by the shaker). Time responses to such excitation profile were gathered, yet amplitudes of MR damper relative displacement were marginally small for both $\mathrm{F}_{\mathrm{s}}$ and $\mathrm{P}_{\mathrm{s}}$ semi-random excitation, so the results presented in Table 2 (RMS displacements divided by RMS force $\mathrm{F}_{\mathrm{s}}$ ) concerning vibration control are questionable (typed in grey font). According to the above remark, presentation of $\mathrm{P}_{\mathrm{s}}$ excitation results was omitted for this test.

\section{Conclusion}

The conducted experimental study along with analyses results presented in other publications, e.g. [24-26], all confirm the sense and advisability of the proposed implementation of MR TVA in a wind turbine nacelle assembly, based on investigation of tower-nacelle model. The potential of MR TVA in tower-nacelle structural vibration reduction at frequency of the $1^{\text {st }}$ bending mode is significant. Vibration control results of the system equipped with MR TVA are improved in relation to the system that emulates standard TVA with linear (viscous) damper, and with passive solutions with constant MR damper input current.

As can be observed, Mod.GND 0.5 algorithm delivers the most preferable responses, and its results are reasonably good over a wide variety of tests, most of all for excitation within 
$1^{\text {st }}$ bending frequency $f_{1}$ neighbourhood range, where a slight improvement may be possible for $(3.15,3.90) \mathrm{Hz}$ range only, which is demonstrated by very low MR damper input current solutions as C3 $150 \mathrm{INV} F r$ or, obviously, 0.0 A open loop system. These solutions, however, suffer from high amplitudes below and above frequency $f_{1}$. The typical for TVA two maxima of frequency characteristics can be clearly observed not only for the open-loop system $0.0 \mathrm{~A}$ and some nonlinear damping control solutions, but also for linear damping $0.6 \mathrm{C} \mathrm{PI1} \mathrm{Fr}$ (although not for $1 \mathrm{C}$ ), or adaptive control ADAPT 0C INV Fr algorithms, i.e. only for the solutions with low damping (e.g. reduced by the factor of 0.6 or zero required damping). The hardly measurable structure inherent damping resulting from, among others, interfacial friction in joints, shaker armature and drive train system damping, linear bearings friction, MR damper sealing and pre-yield friction component, all of them compromised the shape/presence of two apparent maxima of frequency characteristics for some systems. It was also observed that including hysteresis in MR damper inverse model generally improves vibration response of algorithms determining damper desired force $(C, C 3, S Q R T, A D A P T)$, in relation to the use of inverse model without hysteresis.

More analyses are concerned regarding control solutions, among other improving MR damper force tracking algorithm by combining PID-family controller with direct force measurement and improved MR damper inverse model, using Kalman filter [31] for real-time reproduction of velocity signals (especially) [34], and conducting more valuable random excitation tests.

Acknowledgment. This work was financed by the Polish National Science Centre under project no. 2286/B/T02/2011/40.

\section{REFERENCES}

[1] I. Enevoldsen and K.J. Mork, "Effects of vibration mass damper in a wind turbine tower", Mech. Struct. \& Mach. 24 (2), 155-187 (1996).

[2] P. Jain, Wind Energy Engineering, McGRAW-HILL (2011).

[3] U.A. Butt and T. Ishihara, "Seismic load evaluation of wind turbine support structures considering low structural damping and soil structure interaction", European Wind Energy Association Annual Event, Copenhagen (2012).

[4] M.H. Hansen, P. Fuglsang, K. Thomsen, and T. Knudsen, "Two methods for estimating aeroelastic damping of operational wind turbine modes from experiments", European Wind Energy Association Annual Event, Copenhagen (2012).

[5] F. Matachowski and P. Martynowicz, "Analiza dynamiki konstrukcji elektrowni wiatrowej z wykorzystaniem środowiska Comsol Multiphysics", Modelowanie Inżynierskie 13 (44), 209-216 (2012)

[6] C. Bak, R. Bitsche, A. Yde, T. Kim, M.H. Hansen, F. Zahle, M. Gaunaa, J. Blasques, M. Dossing, J.J. Wedel-Heinen, and T. Behrens, "Light rotor: the 10-MW reference wind turbine", European Wind Energy Association Annual Event, Copenhagen (2012).

[7] W. Shan and M. Shan, "Gain scheduling pitch control design for active tower damping and $3 p$ harmonic reduction", European Wind Energy Association Annual Event, Copenhagen (2012).
[8] M. Jelavić, N. Perić, and I. Petrović, "Damping of wind turbine tower oscillations through rotor speed control", International Conference on Ecologic Vehicles \& Renewable Energies, Monaco (2007).

[9] H. Namik and K. Stol, "Performance analysis of individual blade pitch control of offshore wind turbines on two floating platforms", Mechatronics 21, 691-703 (2011).

[10] J.P. Den Hartog, Mechanical Vibrations, Dover Publications, Mineola, NY 1985.

[11] S. Oh and T. Ishihara, "A study on structure parameters of an offshore wind turbine by excitation test using active mass damper", EWEA Offshore, Frankfurt 2013.

[12] A. Tsouroukdissian, C.E. Carcangiu, I. Pineda Amo, M. Martin, T. Fischer, B. Kuhnle, and M. Scheu, "Wind turbine tower load reduction using passive and semiactive dampers", European Wind Energy Association Annual Event, Brussels 2011.

[13] M.A. Rotea, M.A. Lackner, and R. Saheba, "Active structural control of offshore wind turbines", 48th AIAA Aerospace Sciences Meeting Including the New Horizons Forum and Aerospace Exposition, Orlando (2010).

[14] W. Łatas and P. Martynowicz, "Modelowanie drgań układu maszt-gondola elektrowni wiatrowej z tłumikiem dynamicznym”, Modelowanie Inżynierskie 13 (44), 187-198 (2012).

[15] P.H. Kirkegaard et al., "Semiactive vibration control of a wind turbine tower using an MR damper", Struct. Dynamics EURO$D Y N$ 2002, Grundmann\&Schueller, Swets\&Zeitlinger, Lisse (2002).

[16] S. Kciuk and P. Martynowicz, "Special application magnetorheological valve numerical and experimental analysis", Diffusion and Defect Data - Solid State Data. Pt. B, Solid State Phenomena 177 (Control engineering in materials processing), 102-115 (2011).

[17] Lord Rheonetic, MR Controllable Friction Damper RD-1097-01 Product Bulletin, Lord Co. 2002.

[18] J. Snamina and B. Sapiński, "Energy balance in self-powered MR damper-based vibration reduction system", Bull. Pol. Ac.: Tech. 59 (1), 75-80 (2011).

[19] P. Martynowicz, "Development of laboratory model of wind turbine's tower-nacelle system with magnetorheological tuned vibration absorber", Solid State Phenomena, 208, 40-51 (2014).

[20] J. Snamina, P. Martynowicz, and W. Łatas, "Dynamic similarity of wind turbine's tower-nacelle system and its scaled model", Solid State Phenomena, 208, 29-39 (2014).

[21] P. Martynowicz and Z. Szydło, "Wind turbine's tower-nacelle model with magnetorheological tuned vibration absorber: the laboratory test rig", Proceedings of the 14th International Carpathian Control Conference, 238-242 (2013).

[22] TMS, 60 Lbf Modal Shaker, The Modal Shop Inc. 2010.

[23] M. Rosol and P. Martynowicz, "Identification of Wind Turbine Model with MR Damper Based Tuned Vibration Absorber", Journal of Dynamic Systems, Measurement and Control (in review).

[24] P. Martynowicz, "Wind turbine's tower-nacelle model with magnetorheological tuned vibration absorber--numerical and experimental analysis", 6WCSCM:Sixth World Conference on Structural Control and Monitoring: proceedings of the 6th edition of the World conference of the International Association for Structural Control and Monitoirng (IACSM): Barcelona, Spain, ISBN: 978-84-942844-5-8 (2014).

[25] J. Snamina and P. Martynowicz, "Prediction of characteristics of wind turbine's tower-nacelle system from investigation of its 
scaled model", 6WCSCM: Sixth World Conference on Structural Control and Monitoring: proceedings of the 6th edition of the World conference of the International Association for Structural Control and Monitoirng (IACSM): Barcelona, Spain, ISBN: 978-84-942844-5-8 (2014).

[26] P. Martynowicz, "Vibration control of wind turbine tower-nacelle model with magnetorheological tuned vibration absorber locked", Journal of Vibration and Control, DOI: 10.1177/1077546315591445 (2015).

[27] H. Laalej, Z.Q. Lang, B. Sapinski, and P. Martynowicz, "MR damper based implementation of nonlinear damping for a pitch plane suspension system", Smart Mater. Struct. 21, DOI: 10.1088/0964-1726/21/4/045006 (2012).

[28] C. Ho, Z. Q. Lang, B. Sapinski, and S.A. Bilings, "Vibration isolation using nonlinear damping implemented by a feedback-controlled MR damper", Smart Mater. Struct. 22, DOI: 10.1088/09641726/22/10/105010 (2013).

[29] T. Orlowska-Kowalska and G. Tarchala, "Unified approach to the sliding-mode control and state estimation - application to the induction motor drive", Bull. Pol. Ac.: Tech. 61 (4), 837-846 (2014).

[30] V.A. Neelakantan and G.N. Washington, "Vibration control of structural systems using MR dampers and a 'modified' sliding mode control technique”, J. Intell. Mater. Syst. Struct. 19 (2), 211-224 (2008).

[31] M. Rosół and P. Martynowicz, "Implementation of LQG controller for wind turbine tower-nacelle model with MR tuned vibration absorber", Journal of the Theoretical and Applied Mechanics (accepted for publication).

[32] T. Ackermann, Wind Power in Power Systems, ISBN: 978-0-47001267-3, J. Wiley, 2005.

[33] D. Hiriart, J.L. Ochoa, and B. Garcia, "Wind power spectrum measured at the San Pedro Martir Sierra", Revista Mexicana de Astronomia y Astrofisica 37, 213-220 (2001).

[34] P. Martynowicz, "Control of an MR Tuned Vibration Absorber for Wind Turbine Application Utilising the Refined Force Tracking Algorithm", Low Frequency Noise, Vibration, and Active Control (in review). 